\title{
Artivismo feminista: aproximación en tres casos del 8 de Marzo en Uruguay
}

Fecha de recepción: 03/09/2019. Fecha de aceptación: 12/01/2020.

\section{Resumen}

Este artículo analizará tres casos de "artivismo feminista" en Uruguay durante las conmemoraciones del 8 de marzo, Día Internacional de la Mujer Trabajadora. Estas acciones pretenden visibilizar los casos de violencia de género, así como los femicidios en el espacio público utilizando la performance como forma de desarrollar la militancia.

Palabras clave: artivismo, feminismo, femicidio, performance, acción.

\section{Feminist Artivism: an Approach to Three Cases from March 8 in Uruguay}

\begin{abstract}
This article will analyze three cases of "feminist artivism" in Uruguay during the commemorations of March 8, International Women's Day. These actions aim to make gender violence and femicide visible in the public space using performance as a way to develop militancy.
\end{abstract}

Keywords: Artivism, Feminism, Femicide, Performance, Action

\section{Presentación}

Durante 2015 las manifestaciones feministas de índole artística se hicieron ampliamente visibles. Los activismos han sabido utilizar el arte como una nueva forma de propagar sus ideas, ya que la visibilidad es, tal vez, el factor más importante. Este trabajo toma como punto de partida este año, ya que en el mismo se comienza a cobrar visibilidad el pedido de miles de mujeres y agrupaciones políticas y militantes, para que el femicidio (figura especialmente agravada de homicidio a una mujer por su 
condición de género y que llevará penas de hasta treinta años de cárcel) sea tipificado como delito a nivel legal. El cierre de esta investigación es el año 2017, ya que el 22 de diciembre de ese mismo año se promulga dicha ley. Ahora se encuentra aprobada e integrada al Código Penal. Se trata de la Ley 19580: el artículo 3 incorpora el numeral 8 al artículo 312 del Código Penal, Sanción al delito de femicidio. El mismo se tipifica cuando entre la víctima y el victimario haya existido vínculo de índole sexual.

Durante estos tres años se realizó un seguimiento de los acontecimientos performáticos que se han producido en el marco de las conmemoraciones del 8 de Marzo, en el que se recuerda el Día de la Mujer Trabajadora. Se seleccionaron las acciones de dos directoras y de un grupo activista. Las obras escogidas son: La caída de las campanas de Hekatherina Delgado, Diez de cada diez de Valeria Píriz y tres representaciones del colectivo "Decidoras Desobedientas", que se desarrollaron durante estos tres años. Las dos primeras comienzan con una idea individual de las directoras, quienes más adelante llamaron a una convocatoria para la conformación de los elencos que realizarían las acciones. Cabe aclarar que el concepto de elenco varía según cada acción, cuestión que se abordará más adelante. En el último caso, "Decidoras", es una agrupación militante del feminismo que trabaja en equipo y sus obras son producto de una elaboración colectiva de todas sus integrantes.

La conmemoración de 2015 se desarrolló un domingo. Este dato es relevante para pensar el espacio urbano como espacio liminal de algunas teatralidades. Dubatti (2015) considera que la liminalidad se plantea en fenómenos escénicos que nos hacen dudar de la teatralidad del mismo, alejándose del teatro puramente dramático, pero que igualmente conservan características de este (convivio, expectación y poiesis corporal). Para Diéguez (2007), la liminalidad es la forma de antiestructura de la que hoy se sirven los grupos políticos para la manifestación.

Quienes conocen Montevideo, saben que los domingos se realiza una de las ferias más grandes, conocida como "Tristán Narvaja", no solo porque ocupa toda la calle que lleva ese nombre y las aledañas, sino porque concurren miles de personas desde que sale el sol hasta las 15 horas aproximadamente.

Es un punto neurálgico para campañas políticas y propagandas de cualquier tipo. Diez de cada diez comenzaron aquí su intervención, pero las otras performances también se correspondieron con lo que aquí sucedía, ya que con la Coordinadora de Feminismos se pautó que se desarrollaran acciones artísticas en puntos relevantes de la capital uruguaya y esos espacios se correspondieron con lugares en el centro de Montevideo.

Se propondrán aquí diferentes conceptos de "artivismo", vinculados a las performances estudiadas y se analizará el vínculo entre performance, política y modos de militancia artística.

\subsection{Descripción de las acciones}

Dentro de los parámetros que hemos descrito entre artivismo, teatralidad y performance, las siguientes acciones se encuentran dentro de esta égida y serán analizadas teniendo en cuenta su relación con el teatro y con el devenir escénico con un sentido militante en el espacio público.

La caída de las campanas es definida en su página de Facebook" (www.facebook.com/ pg/CAMPANASUY/about/?ref=page_internal) como "una investigación filosófica y artística que aborda la hibridación de lenguajes artísticos -instalación urbana, performance duracional, arte sonoro y ensayo documental- indagando en torno a la política de la intimidad y el duelo: un duelo público". Esta acción se ha desarrollado 
durante todo el 2015 en cada femicidio ocurrido en Uruguay. Los espacios que han sido escogidos mayoritariamente han sido edificios estatales ubicados en el centro de Montevideo y plazas que se encuentran en la misma zona.

Ha sido presentada en otros países como Argentina y Brasil. La cita extraída de las redes delimita el campo por el cual se desarrolla esta performance, pero cabe destacar que las redes no funcionan simplemente como una carta de presentación; en este caso han cumplido una función fundamental, porque la convocatoria siempre se hace a través de las redes sociales. En la misma, se pide que quienes deseen participar vistan completamente de blanco, lleven una campana de mano y asistan media hora antes para hacer un precalentamiento. La cantidad de asistentes varía en cada circunstancia y quienes participan son mujeres cis (persona cuya identidad de género está alineada con el sexo que le asignaron al nacer) o sujetos que se autoperciben como mujeres.

Su secuencia de esta performance consiste en que todos los participantes hacen sonar sus campanas de mano y, de forma individual en el momento que lo consideren necesario, se dejan caer al suelo, permaneciendo allí unos 30 segundos aproximadamente (cada performer permanece allí el tiempo que crea necesario), para luego levantarse y continuar con el sonido de la campana. Esta secuencia se reitera y las caídas se generan en distintos momentos.

La duración de la performance también varía según las circunstancias, pero aproximadamente es de cuarenta minutos. Se estrenó el 8 de marzo de 2015 frente a la Suprema Corte de Justicia. En la conmemoración de 2016 se realizó en la Avenida 18 de Julio y, en 2017 , se realizó nuevamente en la misma avenida, pero frente a la explanada de la Universidad de la República.

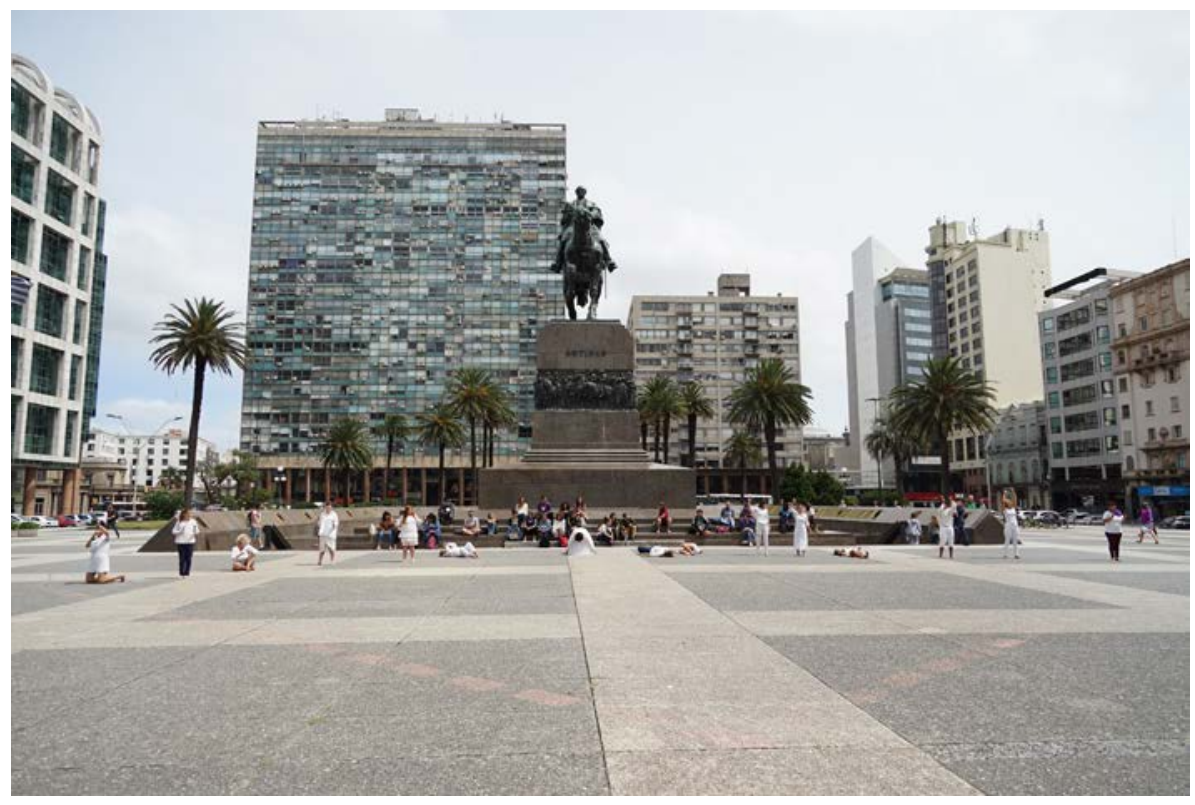

La caída de las campanas, Plaza Independencia de Montevideo, 8 de marzo de 2019. Fotógrafa: Meri Parrado.

Diez de cada de diez es una pieza performática dirigida por Valeria Píriz que se ha realizado cada 8 de marzo desde el 2015, reiterándose en otras fechas de gran relevancia vinculadas al feminismo, así como eventos de artes visuales en Uruguay y en el exterior. La obra comenzó con nueve actrices/performers (mujeres cis) en las inmediaciones de la Feria de Tristán Narvaja, cerca del mediodía, momento en que 
hay mayor concurrencia. Todas se encontraban vestidas con diversos atuendos de color rojo. Interpelaban al público a partir de dos textos que ellas mismas decían: fragmentos de "La mujer, la higiene, su salud, su belleza", del Dr. René Vaucaire de 1929, y citas de una nota del 5 de febrero de 2015 del diario El Mundo de España, titulada "Uruguay no es un país para mujeres". Una vez finalizados los parlamentos y luego de interpelar a los transeúntes con las estadísticas de femicidios y acosos en el país, procedían al armado de una escultura de papel film.

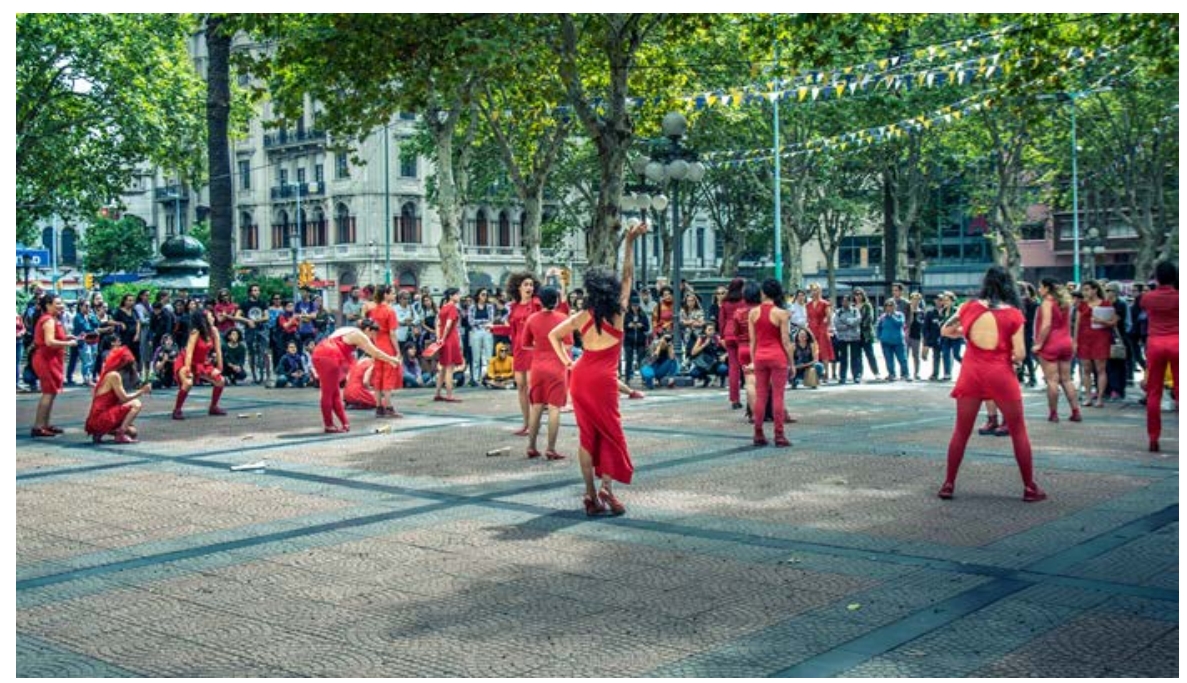

Diez de cada diez, Plaza Libertad de Montevideo, 8 de marzo de 2019. Fotógrafa: Oriana Larrea Díaz.

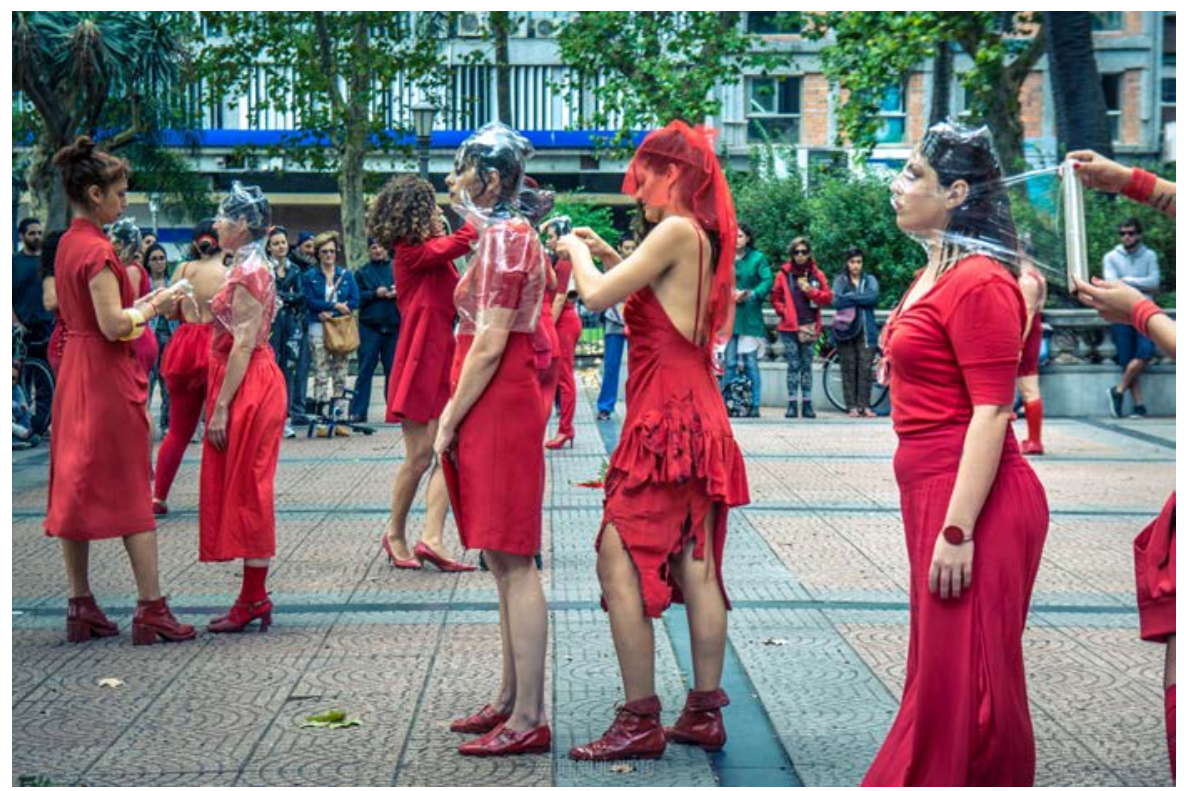

Diez de cada diez, Plaza Libertad de Montevideo, 8 de marzo de 2019. Fotógrafa: Oriana Larrea Díaz.

En las celebraciones del 8 de marzo de 2016 y 2017 creció el número de performers a veinte, cada una de ellas interpretaba un estereotipo femenino distinto y con un atuendo rojo vinculado con el personaje en cuestión. Los textos se reiteraban y finalizaban nuevamente con las esculturas que permanecían pegadas con cinta en el espacio. En 2016, la acción fue realizada en Plaza Independencia, mientras que en 2017 se realizó en el departamento de Treinta y Tres, en la Plaza 19 de Abril. 
"Decidoras Desobedientas" es un grupo activista feminista que, a diferencia de las otras acciones, no trabaja con la figura de una directora; toda su producción consiste en una realización colectiva de sus integrantes. El proceso de trabajo con estas performances es parte de una reconstrucción, ya que ellas no trabajan directamente con una finalidad estética. Dado que por esta razón hay poco registro audiovisual, nos servimos de la memoria grupal. El número de participantes varía en cada instancia, así como las acciones. En cada conmemoración del 8 de marzo realizaron una presentación distinta.

En 2015 presentaron "una intervención callejera" en la explanada de la Intendencia de Montevideo que consistió en la construcción del espacio como escenografía, ambientándolo con utilería vinculada a los estereotipos femeninos delineados por el patriarcado y asociados a la vida doméstica: mesa con mantel, guantes, flores, una Biblia y una cruz católica. Todos estos elementos se ubicaban en los extremos del espacio escénico. En el centro se hallaba una cuerda donde cada una de las integrantes se envolvía, mientras introducía palabras y canciones que reafirmaban los estereotipos femeninos patriarcales. Luego se liberaban de las ataduras de la cuerda frente al público, gritando: "No hay que tenerle miedo a la libertad".

En 2016 esta acción se realizó en la Plaza Independencia. En este caso todas vestían de negro e interactuaban con objetos que se encontraban en el centro del espacio al que poco a poco se acercaban. Los objetos eran: una bolsa de nylon transparente de gran tamaño (donde entra un cuerpo), un vestido negro, un vestido rojo, maquillaje, cuerda, cadenas, una cruz católica y libros. Cada una de las integrantes interactuaba con un objeto y se relacionaba con él a partir del poder que estos ejercen sobre las mujeres. Se iban mirando a los ojos entre ellas, se liberaban de los objetos y se maquillaban con pintura negra, roja y violeta, para luego entre todas finalizar con un texto creado por el colectivo sobre la libertad.

El 8 de Marzo de 2017 la performance se realizó en la Avenida 18 de Julio, frente a la explanada de la Universidad. Todas vestían de negro con coronas de flores en la cabeza, barrían cada una con una escoba de caña y chirca, y a medida que lo hacían decían: "barrer con..." y la frase se iba completando con palabras que se relacionan directamente con el pensamiento machista. Luego de barrer con mucha intensidad, danzaban con las escobas entre las intérpretes, para luego hacer una fogata con las palabras que dijeron y que se encontraban escritas en el centro del espacio escénico. Una vez encendido el fuego, una de las integrantes leyó un texto acompañando la danza alrededor del fuego. 


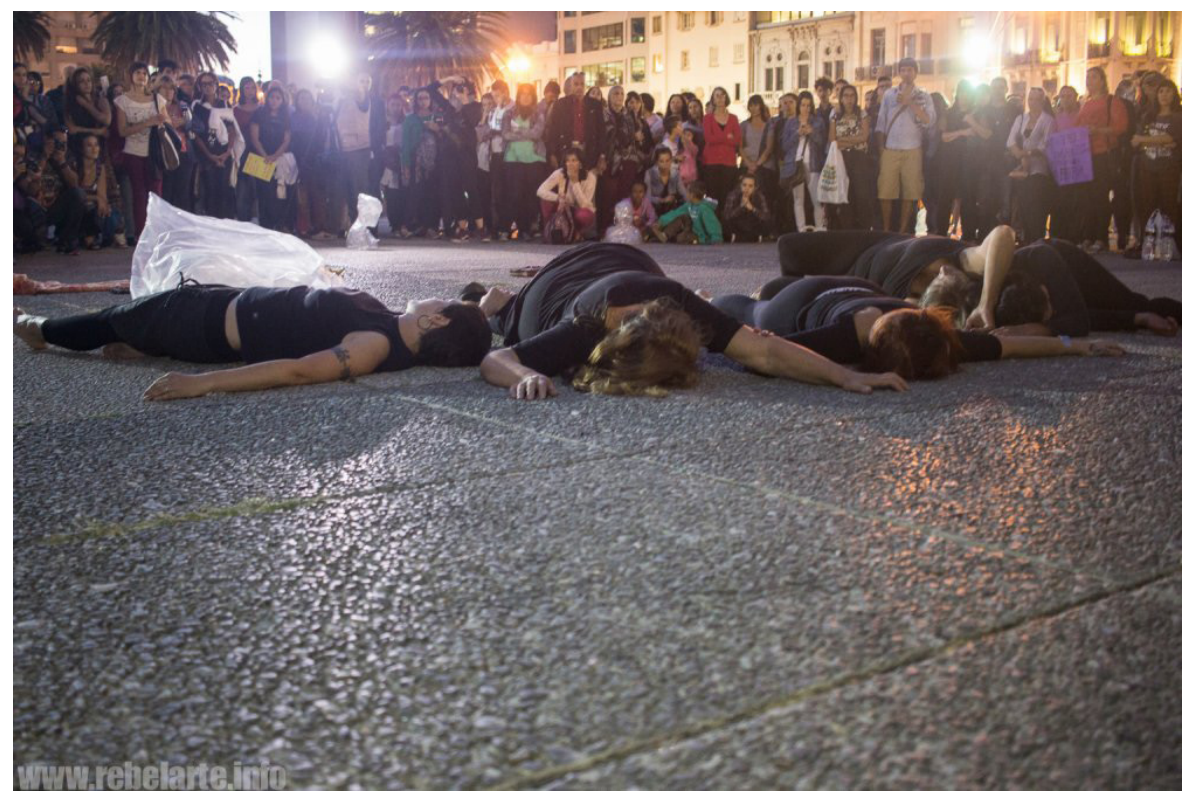

Decidoras desobedientas, Plaza Independencia de Montevideo, 8 de marzo de 2016. Fotografía: Colectivo Rebelarte.

\subsection{Artivismo y performance: un diálogo abiertamente político}

Estas acciones pueden ser consideradas artivistas. El concepto de artivismo surge como un nuevo lenguaje, propio de esta época, y se vincula directamente con aquello que es denominado como arte urbano, debido al uso de la calle como escenario. Según Amina Doherty (2013), el artivismo es una combinación de activista y artista, la cual hace referencia al individuo que utiliza su arte para luchar y pelear contra la injusticia y la opresión por cualquier medio que sea necesario. Es una práctica artística comprometida con alguna lucha política, pero que necesariamente se ubica en otra plataforma o espacio. Se caracteriza por desarrollarse en los espacios urbanos, elaborando una idea en el contexto ofrecido por la ciudad. Las acciones realizadas por estos grupos tienen como principal enfoque la irrupción de los espacios superpoblados en el centro de Montevideo. Las plazas suelen ser los lugares donde más se realizan las acciones, que están desplegadas en puntos que atraviesan la Avenida 18 de Julio, una de las calles más concurridas de la ciudad. Otro factor que se vincula con las tres performances es el impacto generado, porque interpelan socialmente al transeúnte, intentando obtener repercusión.

Como acciones performáticas, son prácticas efímeras y, al dialogar con el entorno, el resultado de la obra no es la performance aislada simplemente como una acción salida de su contexto (Taylor, 2008), sino que es la relación de esta con el contexto, de cuyo vínculo se obtiene como resultado un solo objeto estético. Al pertenecer al arte urbano, tienen puntos en común con el arte de vanguardia y toda expresión artística que se desarrolle en las calles con una voluntad militante.

Se aíslan del mercado artístico, promueven en el espectador/transeúnte la voluntad de darle a conocer un hecho o información con la lucha que llevan a cabo, y es así como se produce el "bucle de retroalimentación" (Fischer Lichte, 2014: 324); a partir del cual actores y espectadores guardan una relación directa en el momento de escenificación, al punto que la acción puede mutar en lo que los receptores hagan o sugieran con su actitud. 
En las conmemoraciones del 8 de marzo, los espectadores mantienen una actitud contemplativa o participan activamente de las acciones. Se suman a la lectura de la proclama final de cada conmemoración y se respetan los espacios que funcionan como escenarios, así como el trabajo de las performers.

Como se mencionó anteriormente, el espacio es fundamental, ya que, dependiendo de la respuesta / acción / reacción del espectador, la performance podrá transformarse de varias maneras. Es necesario tener en cuenta que estas acciones necesitan desarrollarse en ambientes urbanos y públicos; no tienen la necesidad de relacionarse directamente con una institución, sino que parten de la crisis que con ella se mantiene (dichas acciones no están financiadas ni avaladas por ninguna institución).

Esta variación de performance artivista es parte de una acción militante, no académica ni meramente de entretenimiento, por lo tanto, se deslinda de toda articulación con instituciones tanto financieras como del saber. Con esto, definimos la performance artivista como un modo de lenguaje escénico que no siempre se encuentra enmarcado institucionalmente, así como tampoco se encuentra amparado ideológica y artísticamente por ninguna institución que se vincule directamente con las artes escénicas. No es radical la separación entre estas prácticas y las instituciones, ya que actualmente se las ha incluido en cursos académicos. La crisis con las instituciones ${ }^{2}$ no es total, sino parcial. La separación se basa en que estas acciones mantienen un funcionamiento autónomo, así como no generan una dependencia externa con ningún organismo.

Desde la perspectiva de Eva Vico Aladro, se entiende al artivismo como:

(...) un fenómeno global de importancia creciente. Aunque sus antecedentes se remontan décadas atrás, la importancia que ha adquirido como lenguaje cercano a la vida social y a las nuevas generaciones es algo completamente novedoso. En tanto medio o lenguaje de transformación social, puede servir para dar nueva energía a las necesidades de expresión en las ciudades y entornos urbanos actuales (2018: 11)

Las tres agrupaciones se ubican en las coordenadas de lo que podemos denominar como grupos que realizan performances artivistas, acciones que retiran el tránsito convencional a partir del uso del cuerpo del artista/activista como signo, es decir, como plataforma para la expresión de un mensaje de lucha: "El lenguaje del artivismo implica a menudo el uso del sujeto artista como medio para la disrupción de la abstracción, o para evitar la pérdida de capacidad, y para recuperar la libertad de expresión individual" (2018:12).

Más allá de que la acción sea de un colectivo, el compromiso con la causa comienza de forma individual para ejecutarse a nivel grupal. Estas acciones fueron modificando sus elencos y sus temáticas a medida que hubo mayor interés de participación y porque la performance cobró más relevancia como experiencia estética tanto en las artes plásticas y visuales, como en el teatro.

Estas acciones se mantienen en la vida social, ya que su plataforma son los espacios de uso público. A su vez, potencian desde lo artístico un mensaje político que traspasa la

2 La autora del presente trabajo ha sido seleccionada por Espacio de Arte Contemporáneo para la Temporada 22 (año 2016), para realizar un taller/laboratorio sobre performance en artistas mujeres que trabajan sobre la temática de la violencia. Se analizaron obras de las artistas Hekatherina Delgado, Anaclara Talento y Cecilia Vignolo. En 2017, el Dr. Roger Mirza responsable de la maestría en Teoría e Historia del Teatro, le dio el aval para que se dictara un curso de Educación Permanente en Facultad de Humanidades y Ciencias de la Educación (año 2017), y otro curso en 2019, en el Centro Universitario de la Región sobre la performance y artivismo, teniendo en cuenta lo abordado en esta tesis. 
experiencia de un discurso político. Este discurso político se encuentra atravesado por un cuerpo con la intención de ser político, pero también artístico, aunque un término involucre al otro. "(...) la subjetividad del artista se usa como sistema de bifurcación del discurso político, para hacerlo llegar al receptor (Aladro, 2018: 12)".

El cuerpo como signo y canal de expresión ideológica y artística es capaz de establecer su libertad y autonomía a partir del uso de espacios públicos que exaltan el lugar democrático de la performance y que exige un mayor compromiso social antes que una formación artística sólida, aunque también puede ser realizada por sujetos sin trayectoria artística. En los casos de La caída de las campanas y Diez de cada diez, las directoras cuentan con experiencia y formación en arte y política.

El artivismo integra al individuo en la construcción simbólica de la realidad. Es intervención social inmediata. Participación, y despertar activo. Genera en las personas lenguajes para expresarse, convirtiéndose en emisores, y no sólo en receptores. Garantiza la integración del individuo en una construcción de los espacios y contextos colectivos (Aladro, 2018: 15).

La integración de los grupos se basa en la voluntad de construir una voz al unísono con un mismo pensamiento y una misma lucha. El acercamiento a los transeúntes y la comunicación espontánea con los espectadores por parte de los participantes genera un contacto fluido entre el contenido que se quiere transmitir, el acontecimiento y los receptores.

La lucha no se vive únicamente como un modo de militancia, sino que el arte le cede un lugar activo a lo político en comunión con otros artivistas, y plasma un mensaje atravesado por diversos lenguajes artísticos, "conecta directamente con la necesidad de integración práctica", "rescata las funciones normales del arte hacia su desmercantilización", "rompe las barreras académicas y profesionales" y "resignifica espacios" (2018: 16). Lola Proaño establece que el artivismo

(...) es la combinación de arte y activismo con el propósito de impulsar agendas políticas. El artivista se encuentra involucrado muchas veces en arte callejero o en el arte urbano, manifestándose en contra de la publicidad y la sociedad de consumo (2017: 50).

A partir de esta definición, podemos pensar que estas acciones artísticas pueden ser consideradas como parte de entramado de artivismo, ya que las tres postulan una misma idea que pretende ser debatida en la agenda política, particularmente en el marco del feminismo ${ }^{3}$, y que utiliza formas artísticas para su desarrollarlo. Las tres se introducen en el espacio urbano como una forma de independencia de las exigencias artísticas de la institución teatro (de las salas teatrales, de los circuitos oficiales, de las convenciones del teatro independiente, etc.), involucrándose con los agentes sociales de forma más directa, sin la mediación de un espacio acotado a las normas de una disciplina artística determinada. 
Según Proaño, las acciones artivistas cumplen con ciertas características que se convierten en norma. Si tomamos en cuenta su reiteración dentro de las coordenadas de análisis que estamos manejando en lo que podemos denominar performance artivista, encontramos los siguientes puntos:

» Hibridación e interdisciplinariedad: Anteriormente, en la definición de performance consideramos que, en la conformación del concepto del performance art como disciplina, el cruce con otras artes estuvo en su génesis. En estas tres experiencias, veremos el cruce entre performance y teatro, teniendo en cuenta la adaptación que hacen las acciones de los elementos del arte escénico por antonomasia. El uso de vestuario diseñado, la creación de caracteres, la construcción de un texto y la realización de una escenografía, pese a su relación con el espacio urbano, logran que las mismas se definan a partir de estos elementos vinculados a la noción tradicional de teatro.

» Nuevas tecnologías: Las redes sociales se han convertido en el factor fundamental de la difusión, pero también del registro de estas acciones. En el caso de La caída de las campanas el uso de la red social Facebook ha sido fundamental a la hora de realizar la convocatoria para cada instancia. En esta se informa lugar y horario del evento. Además, en la convocatoria se avisa a las interesadas en participar que deberán presentarse media hora antes para un precalentamiento, se informa el vestuario que deben llevar y el instrumento a utilizar.

Lo mismo sucede con Diez de cada diez: la red social funciona como un modo de visualizar el trabajo que realizan en cada instancia, así como su evolución y difusión. A diferencia de la otra acción, no se realiza una convocatoria previa. Esta corre por cuenta de la directora. En "Decidoras", la tecnología no ha sido relevante, no la utilizan como forma de convocatoria, ni como forma de difusión de sus trabajos. Mantienen una metodología por fuera del uso de las redes sociales.

Cooperativismo y autogestión: el colectivo "Decidoras" funciona de manera independiente. Antes de cada instancia en la que realizarán su acción mantienen ensayos previos de colaboración grupal para el desarrollo de las ideas que llevarán a cabo y para lograr el resultado final de lo que muestran. En La caída de las campanas, todo el material, la construcción de ideas y el progreso de la obra son colectivos. Diez de cada diez comenzó siendo una idea de la directora con un inicio de autogestión; luego de ganado un fondo estatal, pudieron invertirlo en la acción y realizarla en otras partes del país.

Niveles de visibilización: las tres agrupaciones logran visibilización a partir de tres factores fundamentales: el uso del espacio público, el vestuario contrastante con los motivos estéticos de la ciudad y los mecanismos de palabra/sonido que desarticulan al espectador transeúnte de su tránsito habitual. Cada acción y grupo buscará su forma de visibilizarse mediante su puesta en escena, vestuario y utilería. Entre ellos, podemos distinguir:

"La caída de las campanas: Vestuario blanco, espacios oficiales y de tránsito continuo, sonido continuado de las campanas (varía según la cantidad de participantes).

»Diez de cada diez: Vestuario rojo, plazas públicas, relato por parte de cada una de las participantes.

»Decidoras Desobedientas: Vestuario negro, calle principal Avenida 18 de Julio o plaza pública, gritos. 
Renuncia a toda centralidad: la línea que divide performance, teatralidad expandida ${ }^{4} \mathrm{e}$ intervención ${ }^{5}$ suele ser muy delgada y lleva a varias confusiones. En estos tres casos, las directoras y participantes han optado por estos términos de forma un poco general. Es frecuente que, en estos casos, no se hable de una disciplina o de un modo de hacer de forma tajante. En el artivismo podría hablarse de generadores de acontecimientos, porque algunas participantes o directoras plantean de forma clara lo que hacen, pero a veces no les interesa acotarse a un concepto, plantean una idea más allá de la teoría. Sus integrantes al dirigirse a las acciones las mencionan tanto como performance, intervención o acción.

La visibilización en el artivismo se debe a la lucha por la ocupación del espacio público. Trabajar desde él y con él sugiere no solo generar un intercambio visual entre transeúntes, sino revalorizar los espacios, que en algunas ocasiones son invisibilizados, pero que a partir del acontecimiento se los resemantiza, invirtiendo el orden de significados cotidianamente asignados e introduciendo unos nuevos.

Manuel Delgado (2013) considera que el artivismo tiene la facultad de analizar las conflictividades urbanas que se dan en el ámbito político actual. De este modo, sugiere que los temas que se presentan en las acciones forman parte de las agendas políticas del momento. El espacio público como escenario cobra mayor centralidad, porque al conformarse las obras a partir de los temas que inquietan en la contemporaneidad, se apela a una democracia real.

Esta dilucidación destinada a resignificar y redignificar la idea de espacio público y rescatarlo de su pecado original como espacio burgués por excelencia, es precisamente la misma que el ciudadano de izquierdas ha reclamado, presumiendo posible encontrar aquello que el idealismo democrático de la pequeña burguesía siempre ha anhelado: una superación e incluso una deslegitimación del viejo encuadre sindical y político de clase (2013: 10).

El uso del espacio urbano manifiesta una postura ideológica, pero también artística. Desacraliza en este caso al teatro burgués/convencional ubicándolo en la esfera pública sin distinción de posibilidades de acceso de determinado público. Este encuadre urbano muestra a su vez un costado deslegitimizado, porque al concretar la acción en el espacio de tránsito, las variables ante el espectador y el espacio son múltiples y con estos factores crece la vulnerabilidad del acontecimiento. A diferencia de lo que ocurre en la experiencia en la sala teatral, la acción precede al público: irrumpe y detiene al espectador, mientras que en el teatro el espectador, de alguna manera, domina la situación al elegir estar allí. En este caso, la espontaneidad es determinante de la relación entre la obra y el espectador.

Las agrupaciones artivistas, según la perspectiva de Julián Gorodischer (2013), se diferencian de las agrupaciones político-partidarias por tener una estructura distinta, debido a que los colectivos artivistas generan el contendido que desean transmitir por sí mismos, y no dependen de un agrupamiento externo, como un partido, para su manutención o al cual representar como voz multiplicadora. En el caso del artivismo feminista, los feminismos son diversos; no hay uno solo; por más que se compartan ideas, la instancia de las acciones artivistas los congregan. Allí radica también el sentido político de estas experiencias: cuando existen ideas en común, la militancia se nutre de ellas y las discrepancias pueden permanecer no visibles.

${ }_{4}$ Cuando la teatralidad se desarrolla en los espacios liminares y se desvincula parcialmente del texto literario, así como de la narratividad, podemos decir que estamos ante la teatralidad expandida (Sagaseta, 2013).

5 El término “intervención” es polisémico. Como acción artística modifica las propiedades de un espacio. Forma parte de lo que puede considerarse "arte efímero", ya que puede abarcar cualquier disciplina artística en el espacio urbano, provocando alguna modificación en el contexto (Tudela, 2008). 
"Un rasgo que comparten muchos de los nuevos activismos es el alto grado de especificidad de las consignas y la defensa de un atributo acotado" (2013:7). En ese sentido, las problemáticas planteadas en estas performances y agrupaciones, así como en los diversos acontecimientos vinculados al feminismo, tienden a la denuncia del gran porcentaje de femicidios en Uruguay. Según las estadísticas del Ministerio del Interior del Uruguay, el porcentaje de femicidios fue el siguiente: 2015-29, 2016-24, y 2017- 23.

Otra marca distintiva que, según Gorodischer, poseen estas acciones es la del uso del cuerpo. Como ya hemos detallado, la performance se basa en el uso del cuerpo como signo. De este modo, se diferencia con el cuerpo del militante político. En estos casos, los cuerpos de mujeres son los que protagonizan las acciones, denunciando la violencia que se ejerce sobre ellas mismas como colectivo.

Los acontecimientos artísticos que aquí se analizan condensan diversos tipos de violencia como la física, psicológica y simbólica, en imágenes que resultan familiares a mujeres que se pueden sentir identificadas, o a los espectadores que pueden entenderlo como una forma de denuncia.

Ana Longoni (2010), por su parte, mantiene puntos en común con los autores anteriormente citados. Considera que el activismo artístico es una expresión que engloba varias prácticas artísticas con la necesidad de tomar una posición y contribuir desde el cambio de una postura política, para hacer del espacio público y escénico un espacio de disenso con un espectador peatón que a su vez es interpelado por el acontecimiento para lograr convertirlo en un espectador activo.

Entre las variantes artísticas que pueden incluirse en la performance, resulta necesario reflexionar en torno a la noción de teatralidad. Ya hablamos de liminalidad y desteatralización en circunstancias donde lo teatral se ve fracturado por los factores de coherencia, texto, narración y construcción de personajes. Mientras haya una ruptura con la teatralidad, más cercano será el tratamiento con una nueva concepción artística. El artivismo suele condensar todos estos elementos para obtener un lenguaje más específico y que se relacione estrictamente con el conflicto que señala.

Lo performático se escapa de la ligazón entre representación y teatralidad y tiende redes para difuminar los vínculos estrechos entre ellas. Estas acciones construyen un puente entre la performance y la teatralidad. El cuerpo transita un devenir en la representación que involucra al movimiento, al vestuario, a la escenografía y, en algunas circunstancias, al texto. Como se aclaró anteriormente, el espacio de estas acciones no está restringido a un público seleccionado o informado, sino que se trata un espacio en el que se da un encuentro casual, proclive al disenso, donde el acercamiento al espectador promueve una construcción discursiva. Se conserva el vínculo con la teatralidad, a modo de lo que Prieto (2009) denomina paradigma centrifugo, porque se parte desde una noción de teatralidad y de elementos que son propios del teatro. Tanto en La caída de las campanas como en "Decidoras", el teatro funciona como elemento inicial a la hora de crear, ya sea desde la improvisación, o con la inclusión de ejercicios teatrales para la creación.

El teatro tiene en sí mismo el lugar del engaño donde puede verse una intencionalidad en la creación de la ficción, mientras que en las acciones están vinculadas a la esfera de lo cotidiano y no pretende hacer creer algo, sino comunicar, informar, poner el pensamiento crítico en la puesta en escena.

Juan Villegas (2005) desarrolla la noción de teatro marginal para referirse a aquellas obras que se encuentran alejadas del sistema debido a su imposibilidad de recibir apoyos económicos y la participación de artistas emergentes o no profesionales. Este 
tipo de hechos artísticos se mantienen en un circuito teatral donde comparte características con la marginalidad, pero a su vez generan independencia con respecto al teatro porque su relación con la sociedad no es económica, sino que es política. No ocupan un lugar hegemónico en el campo teatral, pero sí guardan una relación muy estrecha con las estéticas de vanguardia. Estas características pueden verse en estas acciones feministas.

Ya hace años que museos de arte contemporáneo y algunos espacios teatrales independientes son permeables a la performance o la teatralidad expandida; sin embargo, nos preguntamos por qué es esta la forma que ha encontrado el activismo para desplegar sus ideas. Desde nuestra perspectiva, tiene que ver con algo fundamental que es, el alejamiento teórico de un modo de hacer lo correcto en la performance como disciplina.

Cuando mantenemos cierta rigidez en el quehacer artístico entre la forma y el contenido, la relación entre arte e ideología se volverá inevitablemente compleja. Los activismos necesitan accionar con rapidez y eficacia para dar a conocer una forma de ver el mundo, el acuerdo o el desacuerdo con un suceso; por eso, la performance artivista se organiza de forma independiente ante el factor de la emergencia. No se puede estar atado a una cantidad excesiva de ensayos cuando no hay remuneración económica, tampoco a la memorización de parlamentos y, por último, porque necesita de sujetos comprometidos, antes que de artistas profesionales.

Villegas (2005) considera que el sistema de códigos culturales está conformado según los sectores sociales que lo diseñan. Situar una forma de teatralidad en el espacio público, en la calle, en las plazas, en los monumentos y en los edificios estatales, es un modo de configurar los códigos de este tipo de arte y de quienes participan en él. En estos conceptos de teatralidad y de performance quedan expuestas las vicisitudes económicas de una sociedad y de los artistas cuando el espacio público es intervenido.

Estas experiencias nada tienen que ver con exponer una obra en un museo o alquilar una sala teatral. El espacio legitima, pero no elimina la posibilidad de expresiones. La calle, como lugar público, posibilita un número indeterminado de expresiones y las posibilidades de visibilidad son mayores que en un espacio privado.

El mismo autor establece que el sistema cultural es portador de aquello que utiliza. Es así cómo la calle se convierte en instrumento, pero también en canal de comunicación para un tipo de representación que tiene que ver con democratizar un saber. La calle es el espacio democrático por excelencia. Sumado a la teatralidad inherente a este tipo de acontecimientos, debemos pensar también en otro factor que lo complementa y jerarquiza: lo político.

Si pensamos en acontecimientos artísticos que tengan peso en el ámbito de lo político, este tipo de acciones constituyen casos paradigmáticos. Lo político entendido desde la perspectiva de Chantal Mouffe (2009), como el espacio de poder, conflicto y antagonismo. Estas características tomadas como condiciones de posibilidad de todo proyecto democrático. La autora piensa lo político desde lo agonal.

No solo debido a sus agentes y espacios, sino por la visibilidad cargada de diversas intencionalidades desde los medios de comunicación. Esta es la forma donde la teatralidad cobra fuerza en la polis. Cumple una función dentro del sistema cultural que no es la de entretener, sino la de movilizar al espectador para que observe un conflicto trascendente a nivel social, pero al que todavía hay que hacerle frente, como el femicidio, el machismo y los distintos tipos de violencia de género. 
"En Latinoamérica el desarrollo del teatro ha estado casi siempre atado a la consideración de las desigualdades sociales, económicas y políticas, características que inevitablemente llevan a la aparición de la violencia en todos los niveles de vida" (Proaño, 2007: 51). La violencia como una cuestión de la que se ha ocupado teatro latinoamericano es un factor que determina a estas acciones en forma y contenido. En la forma, porque este tipo de manifestación parte del caos, de la inexistencia de un molde y de un régimen, de la pluralidad de artes y de la hibridez; en el contenido denuncian los femicidios.

Estas acciones intentan representar lo irrepresentable: la muerte. Lo irrepresentable adquiere múltiples formas para hacer visible lo silenciado. Esta es una variante de las diversas formas del teatro latinoamericano que no descansa en la representación mimética. Parte del caos social para sumergirse en el caos de la representación, que es el lugar que ha encontrado para darle forma ante la emergencia del conflicto. Por lo tanto, se plantea una estética de la incertidumbre, ya que el devenir del conflicto puede ser conocido por todos. Sabemos que existen asesinatos de mujeres a manos de sus parejas, sin embargo, el shock generado por una condensación de imágenes que no narran una historia puede resultar más movilizador que la historia en sí misma.

Dentro del mapa del teatro latinoamericano, podemos vincular los cruces existentes entre la performance artivista y el teatro comunitario que Proaño (2007) trabaja. El punto en contacto está dado por la irrupción de los no contados. En este sentido, la voz de las mujeres se ha presentado con mayor fuerza ante las injusticias con más presencia que en otros momentos, como la apertura al "Me Too", así como el despertar de nuevos grupos feministas militantes. Estas convocan a una nueva puesta a punto en la agenda política contemporánea, que va produciendo cambios de gran avance en política como la Ley de Cuotas (es la participación equitativa de personas de ambos sexos en la integración de órganos electivos nacionales y departamentales) en Uruguay. Se puede ver también en la construcción de personajes femeninos independientes y fuertes en series y películas, donde Estados Unidos ocupa un lugar central. La figura de la mujer en la mediatización tiene un mayor espacio y es aquí donde lo político entra en juego.

Este último estallido feminista tiene muy poco tiempo de desarrollo todavía y, en su marco, han surgido voces de las mujeres desde distintas perspectivas, que estaban silenciadas y comienzan a ser escuchadas. En términos generales, el feminismo es una práctica política porque cuestiona la realidad normalizada por categorías. Interrogarla y deconstruirla es repolitizar la realidad. Es así como ese tipo de acciones feministas constituyen una derivación de la teatralidad política en América Latina.

Otro factor político de este modelo de acción es que son parte de un resultado poético híbrido y heterogéneo. Como ya describimos anteriormente, partimos de las relaciones entre teatralidad y performance; sin embargo, lo indescifrable e inclasificable funciona como norma dentro de esta configuración artística. Óscar Cornago (2006) considera que la expresión de la violencia permite la renovación de lenguajes escénicos. Por ejemplo, el carácter performativo de las acciones rescata el rasgo primitivo de los rituales. Para el investigador español, el teatro latinoamericano genera un universo más concreto y material de las diversas formas de violencia por su condición histórica de dependencia y opresión.

Como resultado de ello, el artivismo tiene una cuota importante de teatralidad, porque necesita ejercer la denuncia a partir de la representación de lo irrepresentable: la violencia y la muerte llegan en forma de imágenes espontáneas desprendidas de la mímesis. Esta no es necesaria en el desarrollo de las acciones, porque si queremos encontrar violencia explícita, la encontramos rápidamente en lo cotidiano, puesto estamos inmersos en una cultura donde habitan formas de violencia como espectáculo. 
Las formas de representación no miméticas desde un lugar poético permiten en estos casos entablar una relación mucho más directa con el pensamiento crítico, y todo ello se da gracias a la presencialidad que hasta hoy conserva el teatro y que la performance comparte. Estas prácticas artísticas entablan una relación mucho más espontánea y directa con el público, acercando el arte y la política a la esfera de la cotidianeidad. 


\section{Dibliografía}

》 Alario, M. T. (2008). Arte y Feminismo. España. Nerea.

" Aparicio Guirao, M. (2017). Las prácticas artísticas durante la dictadura cívico-militar uruguaya (1973-1985) y las prácticas artísticas durante la dictadura cívico-militar argentina (1976-1983). Una perspectiva comparada. https://iberoamericasocial.com/las-practicas-artisticas-la-dictadura-civico-militar-uruguaya-1973-1985-las-practicas-artisticas-la-dictadura-civico-militar-argentina-1976-1983-una-perspectiva-comparada/

»Artaud, A. (2003). El teatro y su doble. Argentina: Octaedro.

»Callin, L. (2008). El cuerpo y la política. En Porzecanski, Teresa (Comp.) El cuerpo y sus espejos. Estudios antropológicos culturales (pp. 137-161). Montevideo: Planeta.

»Cornago, O. (2004). Teatralidades de dos mundos: la puesta en escena de la violencia. XVIII Festival Iberoamericano de Teatro de Cádiz.

" Cornago, O. (2006). Teatro y poder: estrategias de representación en la escena contemporánea. https://journals.iai.spkberlin.de/index.php/iberoamericana/ article/view/951

»Cornago, O. (2009). ¿Qué es la teatralidad? Paradigmas estéticos de la Modernidad. Revista Agenda Cultural. Número 158 pp. 1-20.

»Del Campo, A. (2004). Teatralidades de la memoria. Rituales de reconciliación en el Chile de la transición. Santiago de Chile: Mosquito Comunicaciones.

»Delgado, M. (2013). Activismo y pospolítica. Sobre la estetización de las luchas en contextos urbanos. Quaderns -e. Número 18 (2) pp. 68-8o.

»Diéguez. I. (2007). Escenarios y teatralidades liminares. Arte $a$. http://artesescenicas.uclm.es/archivos_subidos/textos/205/escenarios_teatralidades_liminales.pdf

"Doherty. A. (2013). Cuando el arte y el activismo se encuentran: ser joven feminista artivista.https://justassociates.org/es/relatos-de-mujeres/cuando-arte-activismo-se-encuentran-ser-joven-feminista-artivista

"Dubatti, J. (2007). Filosofía del teatro I. Buenos Aires: Atuel.

"Dubatti, J. (2008). Poética comparada: micropoéticas, macropoéticas, archipoéticas, poéticas enmarcadas.https://www.academia.edu/38987591/Dubatti_Jorge_Teatro_y_Poetica_Comparada

»Dubatti, J. (2016). Teatro-Matriz y teatro liminal: La liminalidad constitutiva del acontecimiento teatral. Conferencia en el Programa de Pos- Graduación en Artes Escénicas. Universidade Federal de Río Grande do Sul.

»Estadísticas Ministerio del Interior del Uruguay, división Políticas de Género (2018). Recuperado del día 26, junio.

"Femenías, M. L. (2009). Poder y violencia sobre el cuerpo femenino de las mujeres. Sociologías. Porto Alegre. Año 11. Junio.

"Fischer-Lichte, E. (2014). Estética de lo performativo. Madrid: Abada.

》Foster, H. (2008). Recodificaciones: hacia una noción de lo político en el arte contemporáneo. http://arteyactivismopolitico.blogspot.com/2008/10/texto-halfoster.html 
» Garbatzky, I. (2013). Los ochenta recienvivos. Poesía performance en el Río de la Plata. Argentina: Beatriz Viterbo Editora.

» Geirola, G. (2018). Teatralidad y experiencia política en América Latina (1957-1977). Buenos Aires: Argus a.

" Gelado, V. (2008). Poéticas de la transgresión: vanguardia y cultura popular en los años veinte en América Latina. Buenos Aires: Corregidor.

» González, M. (2015). La organización negra. Performances urbanas entre la vanguardia y el espectáculo. Buenos Aires: Interzona.

»Insúa Lintridis, L. (2017). La construcción de la ciudadanía en las prácticas performativas. Revista Telón de Fondo. Número 25 pp. 102-121.

"Jameson, F. (2008). Las ideologías de la teoría. Argentina: Eterna Cadencia.

» Jameson, F. (2012). Posmodernismo. Argentina: La marca editora.

»Lehmann, Hans-Thies. (2013). Teatro Posdramático. Guadalajara: Paso de Gato.

»Longoni, A. (2011).¿Qué queda del activismo artístico? Revista Ñ. https://www. clarin.com/ideas/cultura_de_la_crisis_o_rkMxXdF3 DQg.html

»Marinas, J. M. (2012). Pensar lo político. Ensayos sobre comunidad y conflicto. Madrid: Biblioteca Nueva.

"Mouffe, Ch. (2009). El retorno de lo político. Barcelona: Paidós.

» Mouffe,Ch.(2015). ¿Quées política? https://www.youtube.com/watch?v=e1gDulAB5Og

»Pavis. P. (2000). El análisis de los espectáculos. Argentina: Paidós.

"Proaño Gómez, L. y Verzero. L. (2017). Perspectivas políticas de la escena latinoamericana. Buenos Aires: Argus a.

»Proaño Gómez, L. (2013). Teatro y estética comunitaria. Miradas desde la filosofía y la política. Buenos Aires: Biblos.

»Proaño Gómez, L. (2017). Artivismo y potencia política. El colectivo Fuerza Artística de Choque Comunicativo: cuerpos, memoria y espacio urbano. Revista Telón de Fondo. Número 26 pp. 48-62.

»Raffino, M. E. (2018). Movimiento Feminista. https://concepto.de/movimientofeminista/

» Rovira, F. (2015). La maté porque era mía. Uruguay: Semanario Brecha. https:// brecha.com.uy/la-mate-porque-era-mia/

» $\mathrm{s} / \mathrm{f}$ (2015) “Vázquez enviará un proyecto de ley para tipificar el delito de feminicidio”. El País. Recuperado del día 30, noviembre.

"Sagaseta, J. E. (2013). Teatralidad expandida. Buenos Aires: Nueva Generación.

» Schechner, R. (2000). Performance. Teoría y prácticas interculturales. Buenos Aires: Universidad de Buenos Aires.

»Segato, R. (2016). La guerra contra las mujeres. Madrid: Traficantes de sueños.

»Stubs, R., Teixeira Filho, F. y Lessa, P. (2018). Artivismo, estética feminista y producción de subjetividad.http://www.scielo.br/scielo.php?script=sci_ abstract\&pid=S0104-026X2018000200220\&lng=en\&nrm=iso\&tlng=pt

» Taylor, D. (2011). Estudios avanzados de performance. México: Fondo de Cultura Económica.

» Taylor, D. (2012). Performance. Buenos Aires: Asunto Impreso. 
» Ubersfeld, A. (1998). Semiótica Teatral. Madrid: Cátedra.

»Uruguay es el país de la región con más muertes de mujeres a manos de sus parejas. (2015). El Observador. Recuperado del día 25, noviembre.

"Verzero, L. (2014). Ocultarse en lugares públicos: Activismo teatral durante la última dictadura argentina. VIII Jornadas de Sociología de la UNLP. Universidad Nacional de La Plata.

"Vico Aladro, E, Javilkova Semanova, Dimitrina, y Bailey, Olga. (2018). “Artivismo: Un nuevo lenguaje educativo para la acción social transformadora”. Revista Científica de Educomunicación. Número 57 pp. 9-18.

»Villegas, C. (2017). Integraciones: Nuevas tecnologías y prácticas escénicas. Chile: Editorial Cuarto Propio.

»Villegas, J. (2005). Historia multicultural del teatro y teatralidades en América Latina. Buenos Aires: Galerna. 